\title{
Exciton luminescence in AIN triggered by hydrogen and thermal annealing
}

\author{
Martin Feneberg, Nguyen Tien Son and Anelia Kakanakova-Georgieva
}

\section{Linköping University Post Print}

\section{Tweet}

N.B.: When citing this work, cite the original article.

Original Publication:

Martin Feneberg, Nguyen Tien Son and Anelia Kakanakova-Georgieva, Exciton luminescence in AIN triggered by hydrogen and thermal annealing, 2015, Applied Physics Letters, (106), 24, 242101.

http://dx.doi.org/10.1063/1.4922723

Copyright: American Institute of Physics (AIP)

http://www.aip.org/

Postprint available at: Linköping University Electronic Press

http://urn.kb.se/resolve?urn=urn:nbn:se:liu:diva-120167 


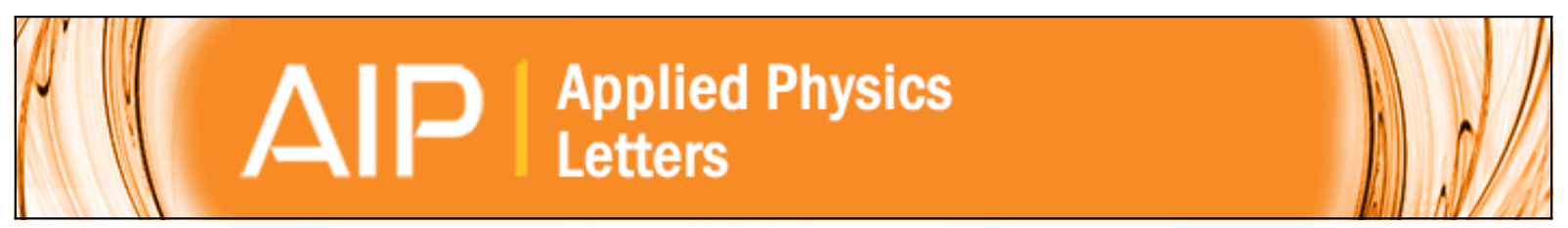

\section{Exciton luminescence in AIN triggered by hydrogen and thermal annealing}

Martin Feneberg, Nguyen Tien Son, and Anelia Kakanakova-Georgieva

Citation: Applied Physics Letters 106, 242101 (2015); doi: 10.1063/1.4922723

View online: http://dx.doi.org/10.1063/1.4922723

View Table of Contents: http://scitation.aip.org/content/aip/journal/apl/106/24?ver=pdfcov

Published by the AIP Publishing

\section{Articles you may be interested in}

Exciton transitions and oxygen as a donor in m-plane AIN homoepitaxial films

J. Appl. Phys. 115, 133503 (2014); 10.1063/1.4870284

Excitonic recombination in epitaxial lateral overgrown AIN on sapphire

Appl. Phys. Lett. 103, 212108 (2013); 10.1063/1.4833246

Beryllium acceptor binding energy in AIN

Appl. Phys. Lett. 93, 141104 (2008); 10.1063/1.2996977

Acceptor-bound exciton transition in Mg -doped AIN epilayer

Appl. Phys. Lett. 85, 2271 (2004); 10.1063/1.1796521

Remote hydrogen plasma doping of single crystal $\mathrm{ZnO}$

Appl. Phys. Lett. 84, 2545 (2004); 10.1063/1.1695440

Frustrated by

old technology?

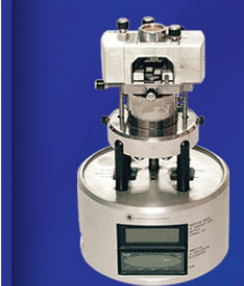

Is your AFM dead

and can't be repaired?

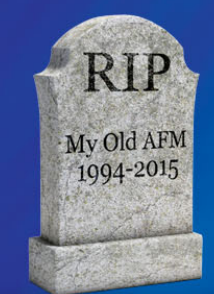

Sick of bad customer support?

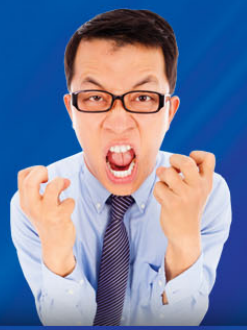

It is time to upgrade your AFM

Minimum $\$ 20,000$ trade-in discount for purchases before August 31st

Asylum Research is today's technology leader in AFM 


\title{
Exciton luminescence in AIN triggered by hydrogen and thermal annealing
}

\author{
Martin Feneberg, ${ }^{1, a)}$ Nguyen Tien Son, ${ }^{2}$ and Anelia Kakanakova-Georgieva ${ }^{2}$ \\ ${ }^{1}$ Institut für Experimentelle Physik, Otto-von-Guericke-Universität Magdeburg, Universitätsplatz 2, \\ 39106 Magdeburg, Germany \\ ${ }^{2}$ Department of Physics, Chemistry and Biology (IFM), Linköping University, 58183 Linköping, Sweden
}

(Received 23 April 2015; accepted 5 June 2015; published online 15 June 2015)

\begin{abstract}
Exciton recombination bands in homoepitaxial AlN layers are strongly dependent on the presence of hydrogen. By thermal treatment under hydrogen-free and hydrogen-rich ambient, respectively, several sharp bound exciton lines are modulated in intensity reversibly. In contrast, the exciton bound at the neutral donor silicon remains unaffected. The mechanism causing these effects is most probably hydrogen in- and out-diffusion into the AlN sample. The main factor determining hydrogenation of AlN layers is found to be molecular $\mathrm{H}_{2}$ in contrast to $\mathrm{NH}_{3}$. We find hints that carbon incorporation into AlN may be closely related with that of hydrogen. Besides photoluminescence spectra of exciton bands, our model is supported by theoretical reports and comparison to the case of hydrogen in GaN. (C) 2015 AIP Publishing LLC. [http://dx.doi.org/10.1063/1.4922723]
\end{abstract}

The development of group III nitrides by metal organic chemical vapor deposition (MOCVD) has been enormously challenged by the incorporation of hydrogen into the epitaxial material. Hydrogen composes most of the growth environment in the MOCVD of group III nitrides and hydrogen atoms incorporate easily at interstitial positions in the crystal lattice. Incorporation of hydrogen into $\mathrm{GaN}$ has long prevented the realization of efficient p-type doping due to the passivation of the common $\mathrm{Mg}$ acceptors by hydrogen involving the formation of $\mathrm{Mg}-\mathrm{H}$ complexes. Demonstrating activation of a $\mathrm{Mg}$ acceptor by using low-energy electron irradiation ${ }^{1}$ or thermal annealing, ${ }^{2}$ and p-type conductivity in $\mathrm{GaN}$, has contributed to the recognition of the winners of the Nobel Prize in Physics 2014. Incorporation of hydrogen into $\mathrm{InN}$ has been speculated as the origin of the background electron concentration well in excess of $10^{18} \mathrm{~cm}^{-3}$.

First-principle calculations have pointed to the effect of hydrogen on the doping and electronic properties of InN, $\mathrm{GaN}$, and AlN. From these calculations, GaN appears as a typical example of semiconductor with amphoteric behavior of the isolated interstitial hydrogen atoms which counteract the prevailing conductivity caused by the dopants. ${ }^{4,5}$ The behavior of the isolated interstitial hydrogen atoms is further related to the formation of $\mathrm{Mg}-\mathrm{H}$ and $\mathrm{Si}-\mathrm{H}$ complexes in GaN. ${ }^{6}$ Alternatively, InN appears as an example semiconductor (together with $\mathrm{ZnO}$ ) in which the isolated interstitial hydrogen atoms behave exclusively as donors. ${ }^{4,5}$ Firstprinciple calculations have found the behavior of the isolated interstitial hydrogen atoms in AlN to be very similar to GaN, i.e., $\mathrm{H}^{+}$dominates in p-type; whereas $\mathrm{H}^{-}$dominates in n-type. ${ }^{7}$ Due to the larger band gap of AIN, certain effects have been predicted as to the significantly larger solubility of hydrogen into AlN than into GaN $;^{7}$ and to the more important role which $\mathrm{H}^{-}$plays in n-type AlN, than in n-type GaN. ${ }^{8}$

AlN has joint the family of widely recognized semiconductor materials relatively recently following the first demonstration of successful n- and p-type doping achieved by

\footnotetext{
${ }^{\text {a) }}$ Author to whom correspondence should be addressed. Electronic mail: martin.feneberg@ovgu.de
}

the intentional incorporation of $\mathrm{Si}$ and $\mathrm{Mg}$ atoms, respectively. ${ }^{9}$ The debate on the doping properties of this wide band gap semiconductor, $6.012 \mathrm{eV}$ at room temperature, ${ }^{10}$ is strongly dominated by resolving the issue of compensation effects under the conditions of intentional Si doping, ${ }^{11}$ and particularly the formation of stable silicon-related DX centers. ${ }^{12}$

AlN is the semiconductor material that has been least subjected to speculations for the effect of hydrogen on its doping properties. A theoretical insight into the potential formation of acceptor-hydrogen and donor-hydrogen complexes is lacking. Any explicit experimental observation that correlates the doping properties of AlN with hydrogen incorporation into the material is also lacking. Here, we show exciton luminescence from homoepitaxial AIN layers, which has been triggered by the hydrogen incorporation into the material during the MOCVD process and further affected by sequence of thermal anneals.

AlN layers were grown in an established MOCVD process $^{13}$ on AlN substrates purchased from a commercial vendor. Trimethylaluminum $\left.\left(\mathrm{CH}_{3}\right)_{3} \mathrm{Al}\right)$ and ammonia $\left(\mathrm{NH}_{3}\right)$ were used as the precursors in the deposition process. While ramping up to the deposition temperature of $1240^{\circ} \mathrm{C}$, the AlN substrate surface was exposed to a gas flow composed of the carrier gases $\mathrm{H}_{2}$, and $\mathrm{N}_{2}$, and the precursor $\mathrm{NH}_{3}$. It was shown earlier that adding $\mathrm{NH}_{3}$ to an $\mathrm{H}_{2}$ flow at temperatures up to $1400{ }^{\circ} \mathrm{C}$ suppresses the decomposition of AlN. ${ }^{14} \mathrm{NH}_{3}, \mathrm{H}_{2}$, and $\mathrm{N}_{2}$ entered the reactor at the gas-flow-rate of $21 / \mathrm{min}$, $25 \mathrm{l} / \mathrm{min}$, and $6 \mathrm{l} / \mathrm{min}$, respectively. Therefore, AlN deposition was conducted under $\mathrm{H}_{2}$ rich conditions, i.e., the gas-flow-rate ratio $\mathrm{H}_{2} /\left(\mathrm{H}_{2}+\mathrm{N}_{2}\right) \sim 0.80$. Process conditions, including gasflow-rates, were the same as those established for heteroepitaxial growth of AlN on $\mathrm{SiC}$ substrates ${ }^{13,15,16}$ with details published elsewhere about the regular surface steps determining the morphology of the homoepitaxial AlN layer as examined by atomic force microscopy. ${ }^{16}$ Photoluminescence (PL) was excited by $193 \mathrm{~nm}$ light of an $\mathrm{ArF}^{*}$ excimer laser. The sample was placed in a liquid helium cryostat allowing varying temperature between $7 \mathrm{~K}$ and room temperature. Emission 
was collected by ultraviolet transparent lenses, dispersed by a grating monochromator, and collected by a liquid nitrogen cooled charge-coupled device camera. The spectral resolution chosen for this study was better $\sim 500 \mu \mathrm{eV}$ at $6 \mathrm{eV}$. For spectra at increased sample temperature, the resolution was lowered to $\sim 2 \mathrm{meV}$. Following PL characterization, the as-grown sample was subjected to a post-growth thermal annealing inside the MOCVD reactor in a gas flow of $\mathrm{N}_{2}$ at a temperature of $900^{\circ} \mathrm{C}$. After second PL characterization, the annealed sample was subjected to a further thermal annealing inside the MOCVD reactor in a gas flow of $\mathrm{NH}_{3}$ and $\mathrm{H}_{2}$ at a temperature of $1000^{\circ} \mathrm{C}$ for $20 \mathrm{~min}$. The sample was thermally annealed at the same process pressure of 50 mbar that was applied for the deposition of the AlN homoepitaxial layer.

The as-grown sample expresses sharp and intense photoluminescence from the near-band edge spectral region which has been observed similarly in earlier studies. ${ }^{10,17-23}$ A high resolution spectrum is presented in Fig. 1. The luminescence is dominated by a donor bound exciton band $\left(\mathrm{D}^{0} \mathrm{X}_{1}\right)$ with fullwidth at half-maximum of $0.8 \mathrm{meV}$ at energy of $6.02716 \mathrm{eV}$. On the high energy side, we find free-exciton recombination at $6.04075 \mathrm{eV}$ which is identified with the ground state of the exciton having $\Gamma_{5}$ symmetry comprised of an electron and a hole from the highest valence band following Refs. 10, 17, and 18. (This is in contrast to Refs. 19-21 where the same free exciton is labeled to have $\Gamma_{1}$ symmetry and the $\mathrm{D}^{0} \mathrm{X}_{1}$ band is thought to be the exciton with $\Gamma_{5}$ symmetry.) The position of the free exciton reveals that the present homoepitaxial AlN layer is virtually strain-free. Furthermore, two additional but weaker excitonic recombinations at lower photon energy are found at $6.01840 \mathrm{eV}\left(\mathrm{D}^{0} \mathrm{X}_{2}\right)$ and $6.01235 \mathrm{eV}$ $\left(\mathrm{Si}^{0} \mathrm{X}\right)$. These two bands are identified by comparing their localization energies, i.e., the energy differences to the free exciton band of $22.35 \mathrm{meV}$ and $28.40 \mathrm{meV}$, respectively, to the literature. We assign them to excitons bound at an unknown neutral donor $\left(\mathrm{D}^{0} \mathrm{X}_{2}\right)^{22}$ and the neutral donor $\mathrm{Si}$ $\left(\mathrm{Si}^{0} \mathrm{X}\right),{ }^{23}$ respectively. For the following analysis, we concentrate on the exciton line $\mathrm{Si}^{0} \mathrm{X}$ and the unidentified but intense $\mathrm{D}^{0} \mathrm{X}_{1}$ dominating the spectrum. When temperature is

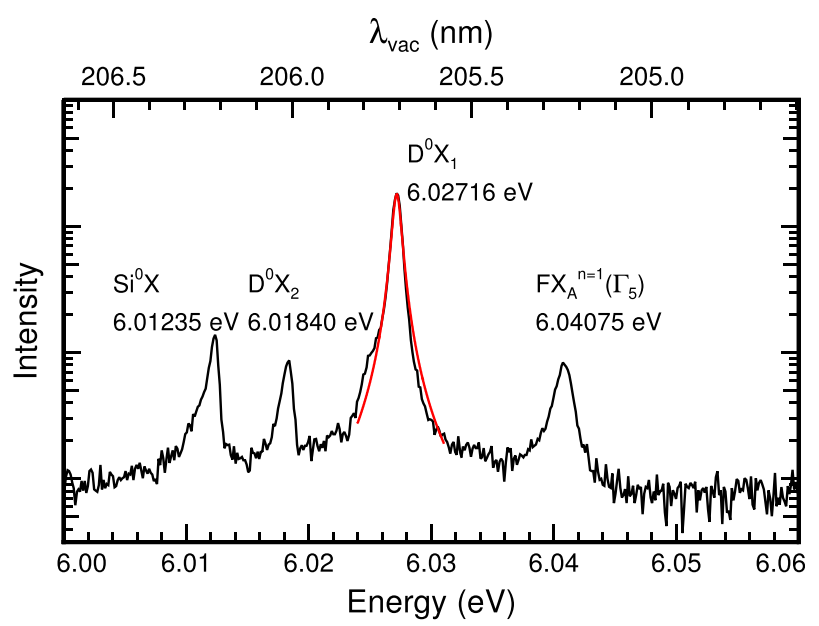

FIG. 1. High resolution photoluminescence spectrum of the as-grown sample at $\mathrm{T}=7 \mathrm{~K}$. The dominant donor bound exciton $\left(\mathrm{D}^{0} \mathrm{X}_{1}\right)$ is fitted by a Lorentzian distribution (red curve) yielding a full-width at half-maximum of $0.8 \mathrm{meV}$. Visible are a free exciton $(\mathrm{FX})$, two donor bound excitons $\left(\mathrm{D}^{0} \mathrm{X}\right)$, and a donor bound exciton at the shallow donor silicon $\left(\mathrm{Si}^{0} \mathrm{X}\right)$. increased, $\mathrm{Si}^{0} \mathrm{X}$ quenches at around $70 \mathrm{~K}$ while $\mathrm{D}^{0} \mathrm{X}_{1}$ proves to be more stable (see Fig. 2). The formation of Si DX-center in $\mathrm{AlN}^{24,25}$ was previously suggested to be responsible for the observed annealing behavior of these donor-bound exciton lines. ${ }^{23}$

The PL properties of the AlN sample change after annealing in $\mathrm{N}_{2}$ drastically. While the $\mathrm{Si}^{0} \mathrm{X}$ emission line remains nearly unchanged and does express the identical temperature dependence as before the annealing step, all other excitonic recombination bands decrease strongly in their intensity or even disappear completely. Figure 3 shows that the unknown donor bound exciton with localization energy of $22.35 \mathrm{meV}\left(\mathrm{D}^{0} \mathrm{X}_{2}\right)$ is nearly invisible after $\mathrm{N}_{2}$ anneal and $\mathrm{D}^{0} \mathrm{X}_{1}$ which was dominating the spectrum in the as-grown sample is now weaker than $\mathrm{Si}^{0} \mathrm{X}$. Furthermore, we note that the free exciton recombination band is also distorted in this spectrum. After the second annealing step in the flow of $\mathrm{H}_{2}$ and $\mathrm{NH}_{3}$, we find that the spectrum of the as-grown sample has fully recovered (Fig. 3).

Thermal annealing in $\mathrm{N}_{2}$ deteriorates the emission properties of AlN, however, no permanent change occurs as the thermal annealing in the flow of $\mathrm{H}_{2}$ and $\mathrm{NH}_{3}$ restores the previous spectrum. The fact that $\mathrm{Si}^{0} \mathrm{X}$ emission remains approximately unchanged throughout the whole procedure rules out a strong impact of any structural changes which might be dependent on the annealing ambient. The remaining possibilities to explain the observed changes include out-diffusion of certain chemical species or passivation of donors. The chemical element being the most likely candidate for diffusion is hydrogen as (i) presence of hydrogen is the main difference between both annealing conditions, (ii) hydrogen is a very small element which is expected to occupy interstitial sites and may thus be removed and introduced completely reversibly, and (iii) hydrogen is known to be a passivating agent in

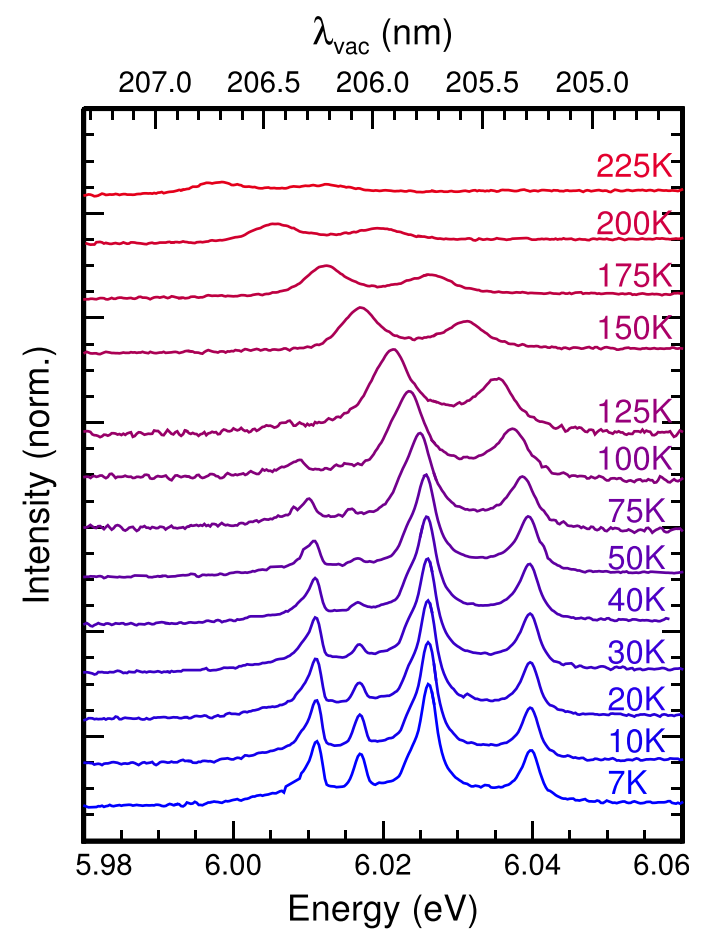

FIG. 2. Temperature dependent photoluminescence spectra of the as-grown sample in logarithmic scale. 


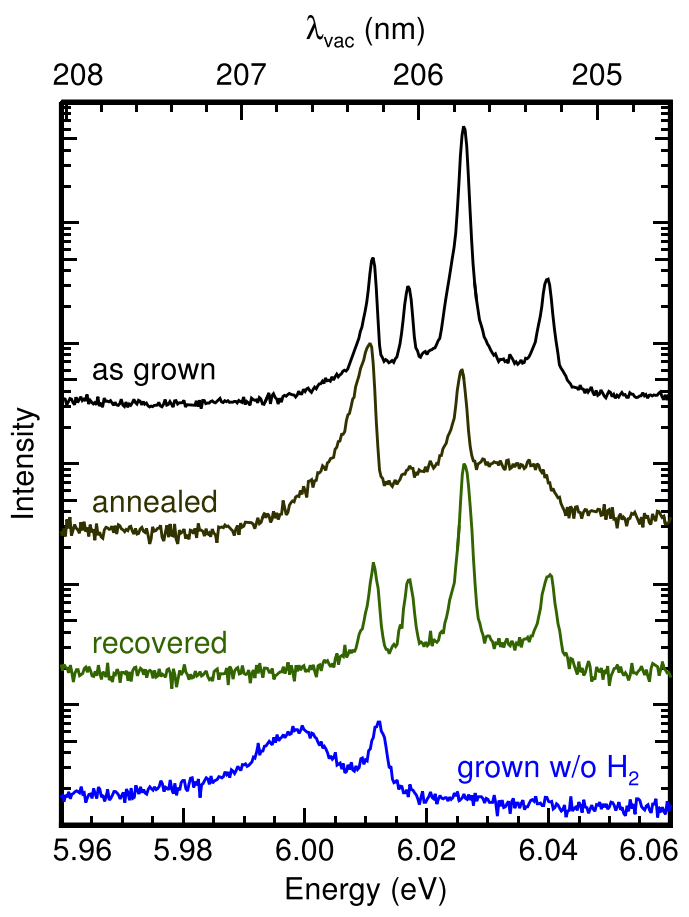

FIG. 3. Low temperature (7 K) PL spectra of the sample (from top to bottom) as grown, annealed, and recovered. At the bottom, the PL spectrum of a different sample which was grown without $\mathrm{H}_{2}$ in the carrier gas is shown for comparison (blue).

group III nitrides, e.g., for the magnesium acceptor in GaN. Already in 2001, Ref. 8 predicted that hydrogen should play a larger role in n-type AIN than in p-type AIN. Atomic hydrogen should then be a compensating acceptor. About hydrogen-donor complexes in AlN little is known from experiment or theoretical calculations.

Generally, our established MOCVD process for AlN on $\mathrm{SiC}$ substrates, in particular, with respect to process temperature and gas-flow-rate of precursors, determines growth kinetics which prevents any major incorporation of the residual impurities silicon and oxygen into the epitaxial layers. In previous study, ${ }^{15}$ the atomic concentration of the residual impurities was measured by secondary ion mass spectrometry (SIMS, Evans Analytical Group). The atomic concentration of the residual impurities silicon and oxygen in a typical high-crystalline quality heteroepitaxial AIN layer was found at the level of $[\mathrm{Si}] \sim 5 \times 10^{17} \mathrm{~cm}^{-3}$ and $[\mathrm{O}] \sim 6 \times 10^{17} \mathrm{~cm}^{-3}$. 15 These values correspond to the values at the typical SIMS instrument detection limit for silicon and oxygen in AIN, respectively. The SIMS instrument detection limit for carbon and hydrogen was $[\mathrm{C}] \sim 2 \times 10^{17} \mathrm{~cm}^{-3}$ and $[\mathrm{H}] \sim 3 \times 10^{17} \mathrm{~cm}^{-3}$. The atomic concentration of the residual impurities carbon and hydrogen in the heteroepitaxial AIN layer was found at the level of $[\mathrm{C}] \sim 1 \times 10^{18} \mathrm{~cm}^{-3}$ and $[\mathrm{H}] \sim 2 \times 10^{18} \mathrm{~cm}^{-3}$ beyond these detection limits. Moreover, the atomic concentration of hydrogen in AlN was found to be by about one order of magnitude higher than the typical atomic concentration of hydrogen in heteroepitaxial layers of $\mathrm{GaN}$ on $\mathrm{SiC}$ and homoepitaxial $\mathrm{GaN}$ layers which is $[\mathrm{H}] \sim 3 \times 10^{17} \mathrm{~cm}^{-3}$. ${ }^{26}$ This may be interpreted as supportive of the expectation for the significantly larger solubility of hydrogen into AlN as into GaN. ${ }^{8}$ The same comparison applies to the levels of the residual impurity carbon, which was typically found at $[\mathrm{C}] \sim 3 \times 10^{17} \mathrm{~cm}^{-3}$ in heteroepitaxial layers of $\mathrm{GaN}$ on $\mathrm{SiC}$ and homoepitaxial $\mathrm{GaN}$ layers. ${ }^{26}$

The incorporation of carbon and hydrogen into the epitaxial layers of AIN (and GaN) must be contributed by the chemical reactions in the boundary layer, and the dissociative adsorption of characteristic reaction species on the crystal surface. As well acknowledged, the growth chemistry of $\mathrm{GaN}$ is dominated by the radical reactions on the surface between species such as $\left(\mathrm{CH}_{3}\right)_{2} \mathrm{Ga}$ and $\mathrm{NH}_{2}$; and $\left(\mathrm{CH}_{3}\right) \mathrm{Ga}$ and $\mathrm{NH}$ along with the release of methane $\mathrm{CH}_{4} \cdot{ }^{27}$ While existence of significant concentration of methane is indicated in the gas-phase, it is not the source of unintentional carbon and hydrogen doping of GaN. In contrast, the formation of methane acts as mechanism for carbon removal. It most probably involves the transfer of an $\mathrm{H}$ atom from a surface adsorbed $\mathrm{NH}_{\mathrm{x} \leq 3}$ to a surface methyl radical $\mathrm{CH}_{3}$, which is produced by the thermal decomposition of the precursor trimethylgallium $\left(\mathrm{CH}_{3}\right)_{3} \mathrm{Ga}$ in the boundary layer (by analogy with the case of MOCVD of $\mathrm{GaAs}^{28}$ ). Alternatively, the growth chemistry of AlN is dominated by the reaction species $\left(\mathrm{CH}_{3}\right)_{2} \mathrm{AlNH}_{2}$ (with further di/trimerization, i.e., $\left.\left[\left(\mathrm{CH}_{3}\right)_{2} \mathrm{AlNH}_{2}\right]_{2,3}\right)$ derived from the adduct $\left(\mathrm{CH}_{3}\right)_{3} \mathrm{Al}: \mathrm{NH}_{3}$ with the associated facile methane elimination in the gasphase. ${ }^{27}$ The strength of the Al-C bond in the reaction species $\left(\mathrm{CH}_{3}\right)_{2} \mathrm{AlNH}_{2}(\sim 79.9 \mathrm{kcal} / \mathrm{mol}$ (Ref. 29)) is larger than the strength of the Al-N bond in the AlN crystal lattice ( $\sim 66.4 \mathrm{kcal} / \mathrm{mol}$ (Ref. 30)), which may be a factor that assists in the carbon incorporation into AlN upon the dissociative adsorption of $\left(\mathrm{CH}_{3}\right)_{2} \mathrm{AlNH}_{2}$ on the crystal surface.

Given that the process temperature is in the same window of $1200^{\circ} \mathrm{C}$ (the case of $\mathrm{AlN}$ on SiC substrate ${ }^{15}$ )to- $1240{ }^{\circ} \mathrm{C}$ (the case of AlN on AlN substrate considered here) and represents a major factor in the incorporation of the residual impurities, ${ }^{15}$ the atomic concentration of silicon, oxygen, carbon, and hydrogen in the homoepitaxial AIN layer is expected at the corresponding level found in the heteroepitaxial AIN layer. Therefore, the AIN homoepitaxial layer with the above-referred unintentional doping characteristics yields the low-temperature exciton luminescence shown in Fig. 1. The subsequent thermal annealing of the asgrown sample in $\mathrm{N}_{2}$ was done under the conditions that rendered the $\mathrm{Mg}$ acceptors electrically active in epitaxial layers of $\mathrm{Al}_{0.85} \mathrm{Ga}_{0.15} \mathrm{~N}$ alloy composition. ${ }^{31}$ Therefore, we expect annealing in $\mathrm{N}_{2}$ to cause the out diffusion of hydrogen. This out diffusion in turn is expected to be the reason for deteriorating the emission properties of AlN.

The exact mechanism how presence of hydrogen increases intensity of the shallow donors at $6.01840 \mathrm{eV}$ and $6.02716 \mathrm{eV}$ is to be clarified. However, the simultaneously influenced free-exciton luminescence opens up the possibility to construct a tentative model. As argued above, the presence of carbon and hydrogen seems to be related while only the hydrogen level can be changed by thermal treatment considerably. When speculating compensation of the carbon deep trap by hydrogen, this would constitute an effective mechanism of luminescence quenching after hydrogen outdiffusion. On the other hand, the bound exciton lines showing clear changes can be directly related to the presence of hydrogen. Candidate complexes are $\mathrm{H}_{\mathrm{I}^{-}} \mathrm{O}_{\mathrm{N}}, \mathrm{H}_{\mathrm{I}^{-}} \mathrm{Si}_{\mathrm{Al}}$, and $\mathrm{H}_{\mathrm{I}^{-}}$ $\mathrm{V}_{\mathrm{Al}}$, which consist of hydrogen and some of the more 
frequently discussed defects in AlN. In contrast, isolated hydrogen in AlN is expected to be a midgap trap if present as interstitial. ${ }^{4}$ This is in agreement with the lack of the $6.02716 \mathrm{eV} \mathrm{D}^{0} \mathrm{X}$ in physical vapor transport grown AlN crystals where only very low hydrogen incorporation is expected due to the very high process temperature $\left(\mathrm{T}>2000^{\circ} \mathrm{C}\right) .{ }^{32}$

Interestingly, the PL of a different AIN homoepitaxial layer does not show exciton bands except the $\mathrm{Si}^{0} \mathrm{X}$ when grown under the same conditions but by substituting the flow of $\mathrm{H}_{2}$ for $\mathrm{N}_{2}$. The spectrum therefore looks very similar to the annealed sample discussed earlier (Fig. 3). However, spectrum of this sample grown in $\mathrm{H}_{2}$ free carrier gas shows an additional relatively broad band centered around $6 \mathrm{eV}$. Origin of this band is presently unclear. It appears that the flow of $\mathrm{NH}_{3}$ alone in the deposition ambient does not result in the incorporation of hydrogen into the AlN layer as to cause the exciton luminescence. Our findings are corroborated by previous studies concluding that the hydrogen produced by $\mathrm{NH}_{3}$ dissociation does not prevent $\mathrm{Mg}$ from being electrically active in $\mathrm{Al}_{0.10} \mathrm{Ga}_{0.90} \mathrm{~N}$ layers grown by MOCVD in $\mathrm{N}_{2}$ ambient. ${ }^{33}$ It is reinforced here, that after the second annealing step in the flow of $\mathrm{H}_{2}$ and $\mathrm{NH}_{3}$, the spectrum of the as-grown sample has fully recovered (Fig. 3). We conclude that the hydrogenation of the AIN layer and related exciton luminescence originates in the $\mathrm{H}_{2}$ carrier gas. It is plausible that under the particular set of annealing conditions dissociation of $\mathrm{H}_{2}$ on the AlN surface and production of atomic hydrogen at a substantial rate takes place, as well as that $\mathrm{H}_{2}$ on the AlN surface is instrumental for the dissociative adsorption of $\mathrm{NH}_{3}$.

In summary, we presented experimental evidence how hydrogen influences presence and intensity of excitonic recombination bands in AlN. Its importance in the growth process mirrored in photoluminescence of exciton recombination bands is not accounted for in earlier studies. Several bound exciton transitions are directly related to the presence of hydrogen which can reversibly diffuse in and out by selecting proper annealing ambient conditions. Particularly, the hydrogenation of the AlN layer was performed in the flow of $\mathrm{NH}_{3}$ and $\mathrm{H}_{2}$. Our findings are in agreement with what is known about hydrogen incorporation into AlN based on theoretical considerations and by comparison to the case of $\mathrm{GaN}$.

A.K.G. acknowledges support from the Swedish Research Council (VR) and Swedish Governmental Agency for Innovation Systems (VINNOVA). A.K.G. and N.T.S. acknowledge support from the Linköping Linnaeus Initiative for Novel Functional Materials (LiLi-NFM, VR). D. Nilsson is acknowledged for taking part in some of the MOCVD runs. E. Janzén is acknowledged for providing additional financial resources. We thank R. Goldhahn for important input and valuable discussion.
${ }^{1}$ H. Amano, M. Kito, K. Hiramatsu, and I. Akasaki, Jpn. J. Appl. Phys., Part 2 28, L2112 (1989).

${ }^{2}$ S. Nakamura, N. Iwasa, M. Senoh, and T. Mukai, Jpn. J. Appl. Phys., Part 131,1258 (1992)

${ }^{3}$ C. G. Van de Walle, J. L. Lyons, and A. Janotti, Phys. Status Solidi A 207, 1024 (2010)

${ }^{4}$ C. G. Van de Walle and J. Neugebauer, Nature 423, 626 (2003).

${ }^{5}$ C. G. Van de Walle and J. Neugebauer, Annu. Rev. Mater. Res. 36, 179 (2006).

${ }^{6}$ J. Neugebauer and C. G. Van de Walle, Appl. Phys. Lett. 68, 1829 (1996).

${ }^{7}$ C. G. Van de Walle and J. Neugebauer, J. Appl. Phys. 95, 3851 (2004).

${ }^{8}$ S. Limpijumnong and C. G. Van de Walle, Phys. Status Solidi B 228, 303 (2001).

${ }^{9}$ Y. Taniyasu, M. Kasu, and T. Makimoto, Nature 441, 325 (2006).

${ }^{10}$ M. Feneberg, M. F. Romero, M. Röppischer, C. Cobet, N. Esser, B. Neuschl, K. Thonke, M. Bickermann, and R. Goldhahn, Phys. Rev. B 87, 235209 (2013).

${ }^{11}$ A. Kakanakova-Georgieva, D. Nilsson, X. T. Trinh, U. Forsberg, N. T. Son, and E. Janzén, Appl. Phys. Lett. 102, 132113 (2013).

${ }^{12}$ X. T. Trinh, D. Nilsson, I. G. Ivanov, E. Janzén, A. KakanakovaGeorgieva, and N. T. Son, Appl. Phys. Lett. 105, 162106 (2014).

${ }^{13}$ A. Kakanakova-Georgieva, R. R. Ciechonski, U. Forsberg, A. Lundskog, and E. Janzén, Cryst. Growth Des. 9, 880 (2009).

${ }^{14}$ Y. Kumagai, K. Akiyama, R. Togashi, H. Murakami, M. Takeuchi, T. Kinoshita, K. Takada, Y. Aoyagi, and A. Koukitu, J. Cryst. Growth 305, 366 (2007).

${ }^{15}$ A. Kakanakova-Georgieva, D. Nilsson, and E. Janzén, J. Cryst. Growth 338, 52 (2012).

${ }^{16}$ D. Nilsson, E. Janzén, and A. Kakanakova-Georgieva, paper no. 7 in Linköping Studies in Science and Technology Dissertation No. 1597 (Linköping University, 2014).

${ }^{17}$ M. Feneberg, M. F. Romero, B. Neuschl, K. Thonke, M. Röppischer, C. Cobet, N. Esser, M. Bickermann, and R. Goldhahn, Appl. Phys. Lett. 102, 052112 (2013).

${ }^{18}$ M. Feneberg, M. F. Romero, M. Röppischer, C. Cobet, N. Esser, B. Neuschl, K. Thonke, M. Bickermann, and R. Goldhahn, Thin Solid Films 571, 502 (2014).

${ }^{19}$ R. Ishii, A. Kaneta, M. Funato, and Y. Kawakami, Phys. Rev. B 87, 235201 (2013).

${ }^{20}$ R. Ishii, M. Funato, and Y. Kawakami, Phys. Rev. B 87, 161204 (2013).

${ }^{21}$ R. Ishii, M. Funato, and Y. Kawakami, Jpn. J. Appl. Phys., Part 1 53, 091001 (2014).

${ }^{22}$ Z. Bryan, I. Bryan, M. Bobea, L. Hussey, R. Kirste, Z. Sitar, and R. Collazo, J. Appl. Phys. 115, 133503 (2014).

${ }^{23}$ B. Neuschl, K. Thonke, M. Feneberg, R. Goldhahn, T. Wunderer, Z. Yang, N. M. Johnson, J. Xie, S. Mita, R. Dalmau, R. Collazo, and Z. Sitar, Appl. Phys. Lett. 103, 122105 (2013).

${ }^{24}$ R. Zeisel, M. W. Bayerl, S. T. B. Goennenwein, R. Dimitrov, O. Ambacher, M. S. Brandt, and M. Stutzmann, Phys. Rev. B 61, R16283 (2000).

${ }^{25}$ N. T. Son, M. Bickermann, and E. Janzén, Appl. Phys. Lett. 98, 092104 (2011).

${ }^{26}$ A. Kakanakova-Georgieva, I. G. Ivanov, C. Hallin, and E. Janzén, Phys. Status Solidi A 202, 739 (2005).

${ }^{27}$ A. Timoshkin and H. F. Schaefer III, J. Phys. Chem C 112, 13816 (2008).

${ }^{28}$ T. F. Kuech, Mater. Sci. Rep. 2,1 (1987).

${ }^{29}$ R. B. dos Santos, R. Rivelino, F. de Brito Mota, G. K. Gueorguiev, and A. Kakanakova-Georgieva, "Dopant species with Al-Si and N-Si bonding in the MOCVD of AlN implementing trimethylaluminum, ammonia, and silane" J. Phys. D (to be published 2015).

${ }^{30}$ S. Keller and S. P. DenBaars, J. Cryst. Growth 248, 479 (2003).

${ }^{31}$ A. Kakanakova-Georgieva, D. Nilsson, M. Stattin, U. Forsberg, A. Haglund, A. Larsson, and E. Janzén, Phys. Status Solidi RRL 4, 311 (2010).

${ }^{32}$ M. Feneberg, R. A. R. Leute, B. Neuschl, K. Thonke, and M. Bickermann, Phys. Rev. B 82, 075208 (2010).

${ }^{33}$ L. Sugiura, M. Suzuki, J. Nishio, K. Itaya, Y. Kokubin, and M. Ishikawa, Jpn. J. Appl. Phys., Part 1 37, 3878 (1998). 